\title{
The building and research of strong contingent of high level human resource in regional normal colleges
}

\author{
Leilei Deng ${ }^{1, a}$ Xian Zhang ${ }^{2}$, Zitong Wang ${ }^{1}$, Da Zhang ${ }^{1}$, Huaixian Wang ${ }^{1}$ \\ ${ }^{1}$ Jilin Agricultural University, Jilin, Changchun 130118, China \\ ${ }^{2}$ Changchun University, Jilin Changchun 130022,China \\ aDeng_II@163.com
}

Keywords: regular institutions of higher learning, high-level personnel, talent strong school

\begin{abstract}
Local regular institutions of higher learning to build a having both ability and political integrity, structure optimization, highly efficient, innovative and international competitiveness of high-level talent team, to achieve the overall goal of school development and discipline building, creating a batch of both at home and abroad have important influence on the leader and academic backbone, improve school academic competitiveness, social influence and international level. Place in the construction of high-level talent team in common colleges and universities at present stage there are many difficulties and problems, this article aims to from the aspects of high-level talent team construction of systems and mechanisms to explore, strive for crack problems in the actual construction process.
\end{abstract}

\section{1 .Introduction}

The local regular colleges insist the strategy of strengthen the school by talents and put the construction of teachers' group during the twelve-five planning. The structure of teachers is optimized and the whole level is improved continually and shows good development situation. What's more, the scale of teachers are developed and their diplomas, professional qualifications and popularity are improved according to the actual requirement by importing the scarce talents.

\section{2 . Main problems of the high-level talents construction.}

2 . 1 Total quantity insufficiencyCompared with the situation of internal students' substantial increase, the high-level talents group scale still cannot meet the teaching and researching demand, what's more, the proportion of teachers to students is still high especially in some new subjects or institutes. Therefore, some institutes are lack of the reserve of the talents and space of adjustment.

To ensure the current teachers' merit pay, some institutes won't receive new teachers, it will cause not only the saturated class hours but the tasks of course construction are hard to reach, what's worse, it will bring the unreasonable construction of the teachers' group ${ }^{[1]}$. Corresponds to the scale enlargement, the teachers' resource is more single which concerns the creation and competitiveness of the teachers' main social resource and the system of circulating source configuration haven't been set up and the group construction of pluralistic teachers is weaker.

2 . 2 The structure's unreasonable.See the total situation of the current teachers' group in local colleges, the unreasonable structure mainly reflects in the lack of high-level creation group and talents with international competitiveness and position of subject champion, the quantity insufficient of outstanding talents。

2 . 3 Personnel training and evaluation mechanism are unsound.From the personnel training, young teachers have become the main force in regular local higher institutions and therefore, it has become the important content and the urgent task for building the group of teachers to cultivate the young teachers dependently since the cultivating work is insufficient and the education cultivating system which supports the development of teachers is not scientific and completed. 
From the evaluation mechanism we can see we haven't built a set of effective evaluation mechanism while the current one emphasizes the result evaluation and is based on the quantification mark of the steering group the institution and the students which does not reflects the difference between the basic rule of talents development and the different courses. Moreover, the quantification evaluation is easy to become formalistic and leads teachers are more likely to get the short-term effect and ignores the long-term development. As we know the fickle academic environment is bad for cultivating innovate talents but the appearance of innovate products, as time goes on it will block the talents' development ${ }^{[2]}$.

\section{3 . The situation of building local regular institutions of higher learning talents group}

Colleges act as the important organization and the cradle to gather and cultivate talents for our country in modernization drive. Currently, our high-level education cause stands on a historical starting point and enters into a new period from grand high-level education country to the powerful one, meanwhile we are facing the unprecedented development opportunity. To realize the economic and social development and the scientific progress, it needs to emphasize the human resource development, technological innovation and the high-level education career development rapidly.

Our country's first medium and long term education planning outlines in 21st century has clearly proposed to give priority to develop education and increase the input of education. The issuing and implementation of the National mid and long-term reform and development Plan (2010-2020), the ministry of education about some ideas improving higher vocational education quality of teaching all and especially the ministry of education of the ministry of finance opinion about the implementation of the innovation ability of institutions of higher learning promotion plan require to cultivate the innovative scientific talents, the imperative professional talents in the important areas, the younger talents, the high quality talents ,the colleges graduates and to import the overseas high-level talents and some other policies which are the strategy of strengthening the colleges and provide the historical chances to fasten the cultivation of the talents. Therefore, it will be the excellent developing period of high-level colleges in the future. Meanwhile, the hierarchical trend is more obvious and the high-level education is facing the unprecedented challenges and there will be great realistic meaning to strengthen the teaching staff ${ }^{[3]}$.

There has been a teaching group with good quality and stable political stand which is equal to the teaching and scientific tasks in the local colleges at present. However, the construction of the teaching group is still facing some new challenges because of the weak resources. Although the structure of the teachers' diploma and the professional technology duties meet the education and developing demand, the proportion of the doctor's degree to the teachers is still very low, what's more, the inbreeding is ubiquitous, the number of academic leaders is still rare and the high-level young talents are lacked and obscure.

The work of building a high-level talents must connect to the cultivation of talents, the subject construction and the structure of the scientific innovative system to improve the whole level, to deeply carry the powerful strategy by talents and to afford the chances for the talents in the next period. It will also increase the number of high-level talents, young academic leader and the backbone of the teachers and lead to a road of sustainable development, the high quality, high level and optimal structure group will be set up gradually.

\section{The main task of building a high-level talents group}

The colleges should take various measures, make the overall planning and gather the professors. After keeping trying, there are a number of the academic leaders and some of whose level may get the international competitiveness. Based on the subject echelon construction and cultivating the middle-aged excellent teachers, we can bring up a group of superior teachers with international competitiveness, explore and build up a new kind of management mode and operating mechanism which fits the demand in the new period. Thus we can further optimize the performance management mode and study to formulate the measures in all grades to make full use of the lever of interest rates and promote the teachers' group construction to develop sustainably. We aim to build up an innovative group with noble character, appropriate scale, optimized structure and great energy. 
What's more, the school will match the philosophy of schooling and give the stable guarantee for talents and support for intelligence ${ }^{[4]}$.

\section{5 . The specific implement in the talents group of local normal colleges}

\section{5 . 1 To cultivate and import the high-level leader talents and boost the construction of innovate group based on the subject construction}

5 . 1 . 1 The subject development planning should be closely emphasized and configure the human resource effectively. We should regard the subject development as the guide of human resource configuration, and enrich the subject development power around the planning so that the construction of teachers' group will match the important subject. We should develop the thought of talents strategy and dispose the relations between the talents in colleges and different subjects, the import of talents and cultivation independently.

5.1. 2 Strengthen the import force of the high-level talents. The key of import work should be transferred to the import of high-level talents to promote the leader talents group construction especially the talents with international background. Therefore, colleges should employ the subject leaders who have great knowledge, innovation and strategy idea and are good at cultivating the young talents from home and abroad to gather a subject group based on the prominent scholars ${ }^{[5]}$.

\section{5 . 2 To deepen the personnel management reform and increase the initiative by innovating} institutions and management, building and completing the encouragement competitiveness and constraint mechanism.

5 . 2 . 1 To deepen the post-appointment system reform by taking the implement of the institution organization position management. Colleges should complete the post-appointment system constantly, strengthen the post-contract management, build and complete every kind of position analysis institution and explicit the premise for job and the job responsibility according to the institution development demand. To formulate a serious of performance assessment mechanism which fits the post settled at school is pretty important, so that it can realize the balanced state between the people and positions. What's more, the colleges can reach the transition from human management to the position management and ensure the position management assessment mechanism will mobilize our technicians' enthusiasm and innovativeness. The position adjustment should be developed initiatively and so that the whole ability of the teachers' group and the good foundation of academic innovate group will be set up.

5 . 2 . 2 To follow the talents' law of development and complete the teachers' evaluation and encouragement mechanism.vGuided by the Scientific Outlook on Development and Talents Development, based on the principle of both ability and political integrity and emphasizing the real result, colleges should explore and build up the scientific teachers' performance management evaluation system and make full guiding role of the system to teachers' development. Therefore the result of assessment will be an important basis in selecting cadres, the position employment and the distribution the reward. Colleges can formulate the mechanism from rigidity to flexibility, from long period to the short to explore the way of assessment and encouragement, research to build up the comprehensive assessment mode on the basis of individual one and to enlarge the achievement for the assessment of the subject leader.

\section{5 . 3 Promote the professional ethics level based on the construction of teachers' morality.}

To set and complete the long-term mechanism of the morality construction including education, publicity, assessment, supervision, encouragement and punishment by publishing, demonstrating and guaranteeing with policy and legal restraint. The mechanisms are following: the clear responsibility organization leader mechanism, diversified publicity mechanism, objective and fair assessment mechanism, multi-participation supervision management mechanism and the effective rewards and punishment mechanism.

5 . 3 . 1 To innovate the teachers' morality education and guide them to aim high. The topic of teachers' morality education should be enrolled in the cultivation of new teachers and excellent 
group, the key teachers and the subject leaders, the socialism core value outlook, the faith education, the legal education and the mental education are mainly emphasized.

5 . 3 . 2 To improve the publicity of teachers' morality and cultivate the good atmosphere of valuing the morality. The publicity of teachers' morality should be put into institutionalization and normalization and be one important part of the publicity work at colleges. Colleges can preach the Education Act, Higher Education Act, Teacher Law and some standards about the morality, publish the University Teacher Occupation Moral Standard and show the modern spirituality of university teachers. We can publish the typical stories of the outstanding teachers in some festivals such as Teachers' Day by the TV, broadcast, newspaper, network, wechat, webo and micro film to build good social atmosphere of advocating the teachers' morality and striving to be the model, as for some hot and difficult topics, we should also deal with and guide them effectively.

\section{Guarantee of mechanism in the construction of high-level talents group}

6. 1 The guarantee of mechanism. The colleges and universities should complete the guarantee of mechanism of import, retaining, encouraging talents, so that the superior talents will be import and the human resource will be stimulated. The assessment system should be set for different grades, levels and to mobilize the enthusiasm and initiative in teaching and researching. The young talent teachers will also get the opportunity to study or further and train abroad and some other conveniences ${ }^{[6]}$.

6 . 2 Guarantee of the campus talents environment construction. Based on the People First, we should improve the service quality and emphasize the human environment construction, build the culture atmosphere and campus environment with the theme of respect, concern, trust and cultivation and deal with the relation of teachers group, teaching guarantee group and management group.

Meanwhile, we should concern and guarantee the benefit of young teachers, provide them the working conditions and combine the way of keeping talents by emotion, career and payment. Therefore the enthusiasm and innovation would be mobilized.

\section{References}

[1] Yonggang Li, A study on the challenges and approaches to the cultural adaptation of high level talents in universities and Colleges [J], Education management in Colleges and Universities, 2016(02).

[2] Peiying Deng. Thoughts on the introduction of high level talents in Colleges and Universities [J], Human resource management, 2015(03).

[3] Ming Wei, Rational thinking on the construction of high level talents in Colleges and Universities [J], Journal of Hubei Radio and TV University, 2013(12).

[4] Fang Cheng, A study on the policy of the introduction of overseas talents with high level [J], Heilongjiang Researches on Higher Education, 2014(03).

[5] Kui Zhu, On the development of high level talents in Colleges and Universities [J]. Science and technology economic market, 2015(07).

[6] Yueyi Zeng, A study on the strategy of the introduction of high level talents in local colleges and universities in Guangdong [J], Journal of Zhaoqing University, 2013(04). 